\title{
Investment casting of nozzle guide vanes from nickel-based superalloys: part I - thermal calibration and porosity prediction
}

\author{
Agustín Jose Torroba', Ole Koeser ${ }^{2}$, Loic Calba², Laura Maestro ${ }^{3}$, Efrain Carreño-Morelli', Mehdi Rahimian ${ }^{4}$,
} Srdjan Milenkovic ${ }^{4}$, Ilchat Sabirov ${ }^{4}$ and Javier LLorca ${ }^{4,5 *}$

* Correspondence:

javier.llorca@imdea.org

${ }^{4}$ IMDEA Materials Institute, C/Eric

Kandel 2, Getafe 28906, Madrid,

Spain

${ }^{5}$ Department of Materials Science, Polytechnic University of Madrid, Madrid, Spain

Full list of author information is available at the end of the article

\begin{abstract}
Investment casting is the only commercially used technique for fabrication of nozzle guide vanes (NGVs), which are one of the most important structural parts of gas turbines. Manufacturing of NGVs has always been a challenging task due to their complex shape. This work focuses on development of a simulation tool for investment casting of a new generation NGV from MAR-M247 Ni-based superalloy. A thermal model is developed to predict thermal history during investment casting. Experimental casting trials of the NGV are carried out and the thermal history of metal, mold, and insulation wrap is recorded. Inverse modeling of the casting trials is used to define accurately some thermophysical parameters and boundary conditions of the thermal model. Based on the validated thermal model, another model is developed to predict porosity in the as-cast NGVs. The porosity predictions are in good agreement with the experimental results in the as-cast NGVs. The advantages and shortcomings of the developed modeling tool are discussed.
\end{abstract}

Keywords: Ni-based superalloys; Investment casting; Nozzle guide vanes; Thermal model; Thermal history; Porosity

\section{Background}

Nozzle guide vanes (NGVs) are important structural parts of gas turbines [1]. NGVs are typically made from Ni-based superalloys because they have to withstand very high temperatures and aggressive environments [2]. Investment casting in vacuum, also often referred to as lost-wax process, is the only commercially used manufacturing route of these parts that have very complex shapes [3]. Large improvements in turbine efficiency can be achieved with improved designs of the NGVs that normally lead to more complex shapes and thinner geometries. However, these innovations are hindered by the complexity of the manufacturing process, which leads to an increasing number of defects (mainly porosity) during investment casting of parts with complex shapes and very thin elements. As a result, the development of investment casting routes for the new generation of NGVs is carried out via a 'trial and error' approach or, in other words, via experimental casting trials. But this strategy is very expensive and time consuming and thus dramatically limits the rate of innovation.

\section{焦 Springer}

(c) 2014 Torroba et al.; licensee Springer. This is an Open Access article distributed under the terms of the Creative Commons Attribution License (http://creativecommons.org/licenses/by/4.0), which permits unrestricted use, distribution, and reproduction in any medium, provided the original work is properly credited. 
Presently, a paradigm shift is underway in which the experimental casting trials are partially replaced by the numerical simulation of the investment casting process to overcome the limitations of standard 'trial and error' approach [3]. Reconfiguration of the mold that was made on the foundry floor can now be made on a computer and simulated. In addition, the thermal history of a casting can be examined by means of simulations, and the effect of the casting parameters on the microstructure and quality of the as-cast parts can be evaluated. For example, Anglada et al. [4] and Rafique and Iqbal [5] successfully performed the simulation of heat transfer during investment casting of prototypes from Ni-based superalloys. A short description of the modeling tools developed to date and their application to casting of Ni-based superalloys is provided below.

\section{Models developed for porosity prediction}

Porosity is known to be the most common defect found during investment casting and dramatically limits the strength and fatigue life of aerospace components [6]. Thus, investment casting foundries strive to minimize, if not eliminate, this insidious and persistent defect. The available modeling strategies for the prediction of porosity can be classified into three main groups, which are briefly described below.

\section{Analytical models}

Computer models describing the formation of microporosity on the scale of the casting are based on volume-averaging methods for the calculation of the local temperature and pressure fields in the inter-dendritic liquid. These quantities are then used to estimate the level of gas segregation and to determine if the conditions for the nucleation of a pore are met. Most of these approaches originate from the pioneering work by Piwonka and Flemings [7], who developed analytical models that range from exact mathematical solutions to asymptotic approximations using 1D Darcy's law for pore nucleation. A constant solidification velocity together with a constant thermal gradient were assumed in these models. In order to obtain a more accurate prediction of the pore size, the gas pressure within the pores was included in the model, leading to a reasonable agreement with experimental results.

\section{Criteria function models}

Criteria functions were developed in the 1950's for dimensioning the size of risers and prevent inter-dendritic centerline shrinkage and porosity in steel plates [8]. Among the different criteria functions proposed, the Niyama criterion is the most widely used in metal casting to predict feeding-related shrinkage porosity caused by shallow temperature gradients [9]. The Niyama function $N_{y}$ is a local thermal parameter defined as $N_{y}=G / \dot{T}$, where $G$ is the local temperature gradient and $\dot{T}$ the local cooling rate. It is assumed that shrinkage porosity will form in regions in which the Niyama parameter is below a given threshold, which should be experimentally determined for each alloy. A dimensionless form of the Niyama function was presented in [10] that accounts for not only the thermal parameters but also the properties and the solidification characteristics of the alloy and it is able to predict the shrinkage pore volume fraction from the solid fraction-temperature curve and the total solidification shrinkage of the alloy. 


\section{Numerical models}

The first model for porosity prediction was developed by Kubo and Pehlke in twodimensions (2D) [11] and was based on the relationship between the fraction of porosity and local pressure. Lee and Hunt [12] simulated the growth of pores due to hydrogen diffusion in Al-Cu alloys using a 2D continuum diffusion model, combined with a stochastic model of pore nucleation. Although the model did not include the effect of pressure drop due to shrinkage, it showed a good correlation with in situ observations of pore growth. Later, Lee et al. [13] developed a multi-scale model of solidification in $\mathrm{Al}-\mathrm{Si}-\mathrm{Cu}$ alloys, including microsegregation and microporosity. ProCAST was used to solve the energy, momentum, and continuity equations to determine the temperature and pressure evolution with time. This information was coupled to a mesoscale model for microstructural development. Carlson et al. proposed a volume-averaged model for finite rate diffusion of hydrogen in Al alloys [14]. They coupled the calculation of the micro/macroscale gas species transport in the melt with a model for the feeding, flow, and pressure field. This was the first work considering hydrogen diffusion in the growth of pores for three-dimensional (3D) calculations. Pequet et al. developed a 3D microporosity model based on the solution of Darcy's equation and microsegregation of gas [15]. The model coupled microporosity with macroporosity and pipe-shrinkage predictions in a coherent way, with appropriate boundary conditions. Later, this approach was improved by developing a porosity model for multi-gas systems in multi-component alloys, including a realistic model for pore pinching $[16,17]$.

\section{Porosity prediction in casting of Ni-based superalloys}

Most of the research on porosity prediction has been focused in $\mathrm{Al}$ alloys and steels $[18,19]$, and the work on Ni-based superalloys is more limited. Simulation of solidification to predict porosity in investment castings from Ni-based superalloys started a long time back; though, very simple geometries were considered in the earlier works. Overfelt et al. [20] developed a computer solidification model for the castings of plates with thicknesses of 2.54, 12.7, and $25.4 \mathrm{~mm}$ made from the In-718 Ni-based superalloy. The model was used to validate and disprove various phenomenological criteria for predicting porosity. The computer model was shown to be effective in predicting unfed centerline shrinkage in the 25.4-mm-thick plates, but it did not provide precise results for the thinner plates. Monastyrskiy [21] proposed a modeling tool based on liquid metal deformation due to solidification to model shrinkage porosity formation in a GS 32 Ni-based superalloy with low gas content. The model predicted the volume fraction and size of the shrinkage porosity. Nucleation of pores depended on the local stress level in the melt and the pore growth was driven by stress relaxation after pore nucleation. Numerical studies of directional solidification under an imposed temperature gradient and cooling rate were in good agreement with experimental data on porosity formation in Ni-based superalloys [21].

Modeling of investment casting of complex-shape parts has shown to be a more challenging task. Kang et al. [22] applied a model based on the dimensionless Niyama criterion to predict the formation of microporosity in a Ni-based superalloy casting containing complex shapes with thin walls. The theoretical predictions of microporosity showed reasonable agreement with the experimental results, though they underestimated 
the porosity content in the complex thin-wall regions. However, the model was not suitable for the shrinkage porosity prediction in the thick parts of the casting, since those sections often formed isolated liquid pools.

In this work, an advanced modeling approach is applied to the development of a new generation of NGVs with complex shape for aero engines. The objective of this work is twofold. Firstly, a thermal model capable of predicting the thermal history during investment casting of the new generation NGVs is developed. The principles of the thermal model were earlier described by Calba and Lefebvre [23]. Once the developed thermal model is validated against experimental results, the overall casting process can be analyzed in detail. The second aim of the present work is to simulate the development of defects in the as-cast NGVs (such as shrinkage porosity) and the final grain structure. The present manuscript consists of two parts and this (first) part focuses on the development and validation of the thermal model and the porosity prediction tool.

\section{Material and experimental procedures}

Investment casting of the NGVs was carried out using MAR-M247 Ni-based superalloy. The chemical composition of the material is presented in Table 1. The MAR-M247 superalloy is characterized by high temperature strength and excellent corrosion and oxidation resistance at elevated temperatures [24].

The ceramic molds for the experimental casting trials were prepared using the standard manufacturing route. The wax pattern for the NGV was prepared via injection molding and then assembled with a wax feeding system. The obtained wax cluster was immersed into a ceramic slurry and allowed to dry, and this step was repeated until the desired thickness of ceramic mold was reached. The assembly was dewaxed in an autoclave for $15 \mathrm{~min}$ at elevated temperature and high pressure. To burn the wax remains, the ceramic cluster was fired at $900^{\circ} \mathrm{C}$ for $1 \mathrm{~h}$. Finally, the interior of the ceramic cluster was thoroughly rinsed.

The ceramic cluster was wrapped by an insulation layer (made from kaolin wool), having a thickness of $13 \mathrm{~mm}$ and was preheated to $1,200^{\circ} \mathrm{C}$. The geometry and mesh for the model, including different cross sections, are presented in Figure 1b. Before entering the casting furnace, the thermocouples for recording the thermal history during investment casting were quickly set on the assembly. The equipment for in situ temperature measurements consisted of $\mathrm{K}$ - and $\mathrm{S}$-type thermocouples and a standalone data logger able to withstand high vacuum $\left(10^{-3} \mathrm{mbar}\right.$ ), magnetic fields (coming from the induction furnace), and thermal radiation due to the high temperature of the melt. Thermocouples were placed at defined points in the insulation wrap, ceramic mold, and metal. Temperature in the wrap was measured with a thermocouple placed in the center of the wrap layer (marked by a blue spot in Figure 1c). Shell temperature was measured with a thermocouple placed on the leading edge of one external airfoil. Three thermocouples were used to measure the temperature in the alloy but only the results of one of them are shown because the other thermocouples failed during investment casting. The location of each thermocouple is illustrated in Figure 1c, and it was identified by

Table 1 The chemical composition of the MAR-M247 Ni-based superalloy

\begin{tabular}{llllllllll}
\hline $\mathbf{N i}$ & $\mathbf{C}$ & $\mathbf{C r}$ & $\mathbf{C o}$ & $\mathbf{M o}$ & $\mathbf{W}$ & $\mathbf{T a}$ & $\mathbf{A l}$ & $\mathbf{T i}$ & $\mathbf{H f}$ \\
\hline Base & 0.15 & 8.4 & 10 & 0.7 & 10 & 3.1 & 5.5 & 1.05 & 1.4 \\
\hline
\end{tabular}




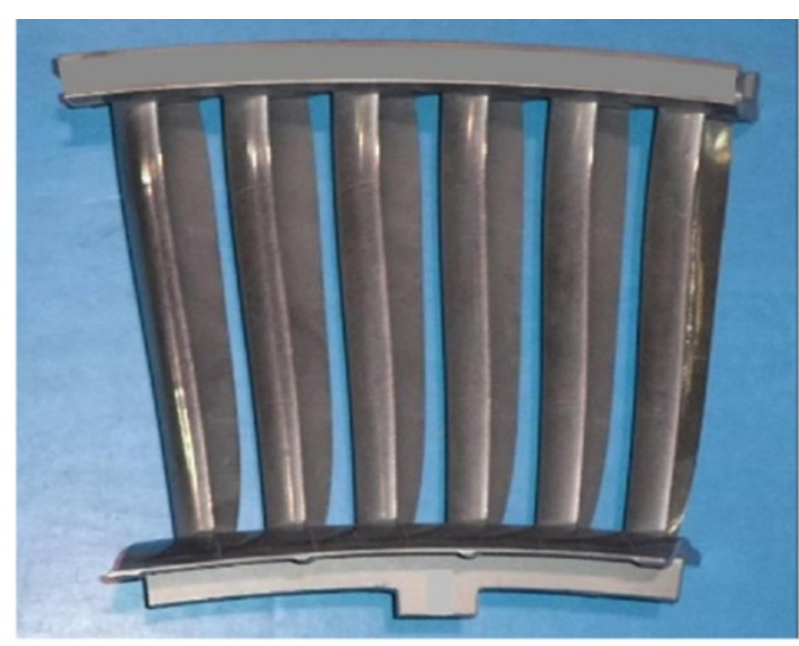

a)
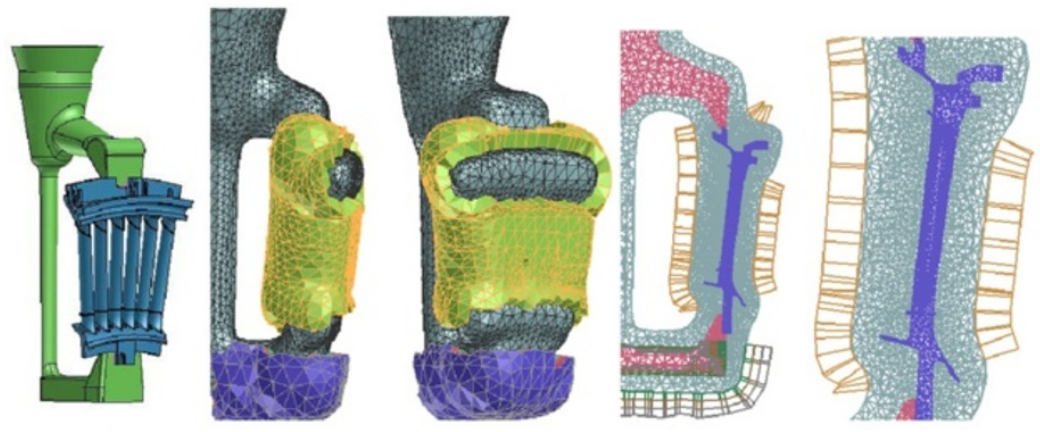

b)
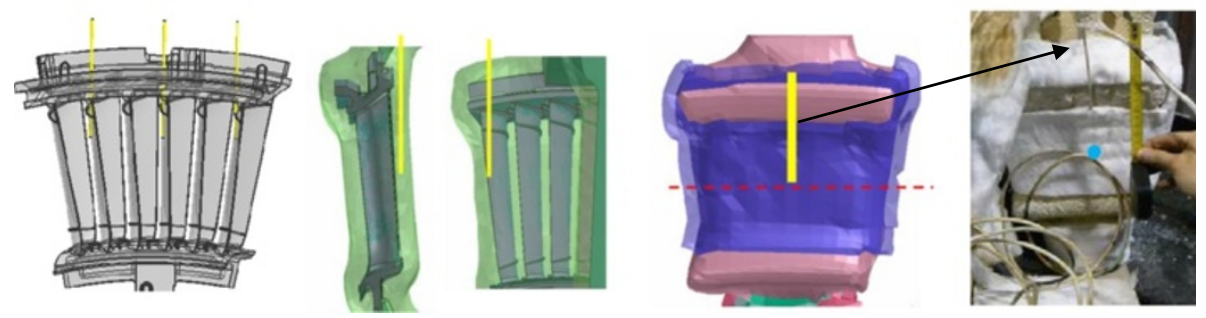

c)

Figure 1 The NGV, model and mesh of the model for half shell, and location of thermocouples. a) The NGV produced by investment casting process; $\mathbf{b}$ ) model and mesh of the model for half shell with insulation wrapping; c) location of thermocouples (in yellow color) to measure temperature on the alloy (left in gray color), shell (middle in green color), and insulation (right in violet color).

nodes in the thermal model (see 'Development of the thermal model' section). The preheated assembly was placed in the vacuum casting furnace where the ceramic mold was filled by the molten metal poured at $1,549^{\circ} \mathrm{C}$ with a melt pouring velocity of $1,700 \mathrm{~mm} / \mathrm{s}$. The assembly was then removed from the furnace and allowed to cool. The thermal history at defined nodes of the metal, the ceramic mold, and the wrap was recorded.

The as-cast NGV (Figure 1a) was cut into smaller specimens for the analysis of porosity. The selected areas for porosity evaluation are shown in the 'Porosity characterization in 
the as-cast new generation NGV and experimental validation of the model' section. The specimens for porosity characterization were ground and polished to the mirror-like surface using standard metallographic techniques. The optical microscope OLYMPUS BX51 was used for porosity characterization. At least three images were taken from each area of interest. Quantitative analysis of porosity (pore size and porosity volume fraction) was performed using ANALYSIS software. The pore size was given by the equivalent circle diameter due to the complex shape of pores.

\section{Modeling}

A modeling approach to investment casting of the new generation NGVs should allow the definition of the cast component, gate, mold, and insulation wrapping configuration and geometries. Starting from the component geometry, the casting process can be gradually developed and optimized, and critical design decisions can be made. Such a model has to be able to cover issues such as heat transfer (including radiation, convection, and conduction), mass transfer (mainly fluid dynamics), and phase transformations, considering at any moment the conservation of mass, momentum, and energy. And it should be able to assess the influence of the geometric and physical parameters on the porosity and structure of the ascast NGVs. For investment casting of the new generation NGVs, most geometrical parameters such as gating, mold thickness, and wrapping scheme are already defined by the manufacturer, but most of the physical parameters remain unknown. The development of the modeling tool and definition of the thermophysical parameters are described below.

\section{Thermal model}

\section{Development of the thermal model}

The basis for reliable modeling of investment casting is a very accurate prediction of the thermal history at each point of the cast. Development of the thermal model requires the optimal selection of the thermophysical parameters along with the proper establishment of boundary conditions as noted in the ASM Handbook [25]. It should also be noted that each manufacturing process has unique boundary conditions that have to be identified, understood, and characterized for the specific application being simulated. The boundary conditions can also be equipment specific, meaning that a furnace may not give rise to the same boundary conditions as another furnace under the same nominal processing conditions.

Mold filling during investment casting was modeled using the three-dimensional finite element solver ProCAST (a trademark of ESI group) by solving the conservation of mass, momentum, and heat flow equations [26]. Conservation of mass is enforced through the continuity equation

$$
\frac{\delta \rho}{\delta t}+\frac{\delta\left(\rho u_{i}\right)}{\delta x_{i}}=0
$$

where $u_{i}$ is the corresponding component of the velocity and $\rho$ stands for the density. The momentum equation as used in ProCAST is given by

$$
\rho \frac{\delta u_{i}}{\delta t}+\rho u_{j} \frac{\delta u_{i}}{\delta x_{j}}+\frac{\delta}{\delta x_{j}}\left(p \zeta_{i j}\left(\mu+\mu_{T}\right) \frac{\delta u_{i}}{\delta u_{j}}\right)=\rho g_{i}-\frac{\mu}{K p} u_{i}
$$


where $\zeta_{i j}$ is the Kronecker delta, $p$ the pressure, $g_{i}$ the gravitational acceleration, $\mu$ the viscosity, $\mu_{T}$ the eddy viscosity, and $K p$ the permeability. These equations are solved under the assumption that the spatial derivatives of viscosity are small and that the fluid is nearly incompressible.

During investment casting, heat flows by conduction through the metal, ceramic mold, and insulation wrap and is removed from the surface by natural convection and radiation. The heat flow is transient, i.e. the temperatures in the casting, mold, and insulation wrap change with time. The governing partial differential equation of heat flow by conduction is expressed as

$$
\rho \frac{\delta H}{\delta T} \frac{\delta T}{\delta t}-\nabla[K \nabla T]-S(r)=0
$$

where $\nabla=\frac{\partial}{\partial x}+\frac{\partial}{\partial y}+\frac{\partial}{\partial z}, T$ stands for the temperature, $t$ for the time, $K$ for the thermal conductivity, $S(r)$ is a spatially varying heat source, and $H$ the enthalpy of solidification, which encompasses both the specific heat term $\left(c_{p}\right)$ and the evolution of latent heat $(L)$ during solidification according to

$$
H(T)=\int_{0}^{T} c_{p} d r+L\left(1-f_{s}(T)\right)
$$

where $f_{s}$ is the fraction of solid.

Initial and boundary conditions for the resolution of previous equations are applied on temperature, velocity, pressure, fixed turbulent kinetic energy, fixed turbulent dissipation rate, and specific, convective, and radiation heat flux. An iterative algorithm is used to simulate solidification by solving Equation 2, finding a coherent solution between enthalpy and temperature results. Further details about this strategy can be found in [27,28].

To solve the complex view factor radiation capability, ProCAST uses a net flux model, in which an overall energy balance for each participating surface is considered rather than tracking the reflected radiant energy from surface to surface. At a particular surface $i$, the radiant energy being received is denoted $q_{\mathrm{in}, i}$. The outgoing flux is $q_{\text {out }, i}$. The net radiative heat flux is the difference of these two.

$$
q_{\text {net }, i}=q_{\text {out }, i}-q_{\text {in }, i}
$$

Utilizing the diffuse gray-body approximation, the outgoing radiant energy can be expressed as:

$$
q_{\text {out }, i}=\sigma \varepsilon_{i} T_{i}^{4}+\left(1-\varepsilon_{i}\right) q_{i n, i}
$$

The first term of this equation represents the radiant energy which comes from direct emission. The second term is the portion of the incoming radiant energy which is being reflected by surface $i$.

The incoming radiant energy is a combination of the outgoing radiant energy from all participating surfaces being intercepted by surface $i$. Specifically, the view factor $F_{i-j}$ is the fraction of the radiant energy leaving surface $j$ which impinges on surface $i$. Thus,

$$
q_{\text {in }, i}=\Sigma_{j=1}^{N} F_{i}-j q_{o u t, i}
$$

where $N$ is the total number of surfaces participating in the radiation model and the view factors are calculated from the following integral. 


$$
F_{i-j}=\frac{1}{A_{i}} \int_{A j A i} \frac{\cos \theta j \cos \theta i}{\pi r^{2}} d A_{i} d A_{j}
$$

where $A_{i}$ is the area of surface $i, \theta_{i}$ the polar angle between the normal to surface $i$ and the line between $i$ and $j$, and $r$ the magnitude of the vector between surfaces $i$ and $j$.

Traditionally, Equation 8 is evaluated by numerical integration, either in the form shown or converted into an equivalent line integral. In ProCAST, the view factors are computed using a proprietary technique.

Solving Eq. 6 for $q_{\mathrm{in}, i}$ yields:

$$
q_{\text {in }, i}=\left[\frac{1}{1-\varepsilon_{i}}\right]\left(q_{\text {out }, i}-\sigma \quad \varepsilon_{i} T_{i}^{4}\right)
$$

Combining Equation 9 with Equation 7 gives a relationship involving the outgoing radiant fluxes only. These outgoing fluxes are known as radio sites. The final form is:

$$
\sum_{j=1}^{N}\left(\zeta_{i j}-\left(1-\varepsilon_{i}\right) F_{i}-j\right) q_{\text {out }, j}=\sigma \varepsilon_{i} T_{i}^{4}
$$

where the Kronecker delta $\zeta_{i j}$ has been included to incorporate the diagonal term. Since there are equations of the form (10), a simultaneous solution is required for a large nonsymmetric system. Because of the reciprocity relation, $A_{j} F_{i-j}=A_{j} F_{j-i}$ can be transformed into a symmetric form which is more economical to solve. Multiplying (10) by

$$
\frac{A_{i}}{1-\varepsilon_{i}}
$$

yields

$$
\sum_{j=1}^{N}\left(\frac{A_{i}}{1-\varepsilon_{i}} \zeta_{i j}-A_{i} F_{i-j}\right) q_{\text {out }, j}=\frac{A_{i}}{1-\varepsilon_{i}} \sigma \varepsilon_{i} T_{i}^{4}
$$

which is solved for the vector of radiosities, $q_{\mathrm{out}, i}$. The net radiant flux is obtained by combining Equation 5 and Equation 9 that gives

$$
q_{\text {net }, i}=\left[\frac{\varepsilon_{i}}{1-\varepsilon_{i}}\right]\left[\begin{array}{ll}
\sigma & T_{i}^{4}-q_{\text {out }, i}
\end{array}\right]
$$

This heat flux then appears as a boundary condition for the heat conduction analysis in ProCAST.

Several software packages were used to generate the thermal model. The NGV design was created with SolidWorks software (powered by Dassault Systems SolidWorks Corporation), while the feeding system was created with Unigraphics software (powered by Unigraphics Solutions Incorporation). Both packages are linked to the casting simulation software ProCAST. Surface and volume meshes were generated by Visual-Mesh (ProCAST software package), considering a maximum distance between nodes of $2 \mathrm{~mm}$ inside the NGV, and $6 \mathrm{~mm}$ for the gating system and pouring cup. The investment casting ceramic mold was composed of layers which were created by ProCAST 3D-Mesh. The ceramic mold has an average thickness of $13 \mathrm{~mm}$. The thickness of the insulation wrap was also $13 \mathrm{~mm}$ and was created and meshed, following the same 
procedure. Only one half of the mold was considered due to symmetry (Figure 1b) in order to speed up the simulations.

Data from different sources were carefully analyzed to assign the thermophysical properties to all the components of the casting system. Those sources include the ProCAST database which was described in detail by Pequet et al. [15], experimental data from industrial companies (Precicast Bilbao and Precicast Novazzano), as well as technical references from previous similar exercises. The thermophysical properties of MAR-M247 Ni-based superalloy (including temperature-dependent thermal conductivity, density, specific heat, and viscosity) were extracted from the ProCAST database (Table 2). Figure 2 illustrates dependence of these properties with temperature. The values of the liquidus and solidus temperatures $\left(1,366^{\circ} \mathrm{C}\right.$ and $1,266^{\circ} \mathrm{C}$, respectively) were also taken from the ProCAST database. It should be noted that a comparison with the Lever Rule model and Scheil model (both described in the ASM Handbook [29]) was made to confirm these data.

Regarding the ceramic mold and wrap insulation, the density and specific heat as functions of temperature were taken from the ProCAST database (Table 2). Values for the thermal conductivity as a function of temperature (Figures 3a and 4a) were obtained by an inverse simulation procedure by comparing the simulation results for simple casting geometries with experimental data generated earlier by Precicast Bilbao. The description of the inverse simulation procedure can be found in O'Mahoney and

Table 2 Thermophysical properties and boundary conditions used in the thermal model

\begin{tabular}{|c|c|c|}
\hline Material & Property (units) & Value \\
\hline \multirow[t]{6}{*}{ MAR-M247 } & Thermal conductivity $\left(\mathrm{W} \cdot \mathrm{m}^{-1} \cdot \mathrm{K}^{-1}\right)$ & $15-35^{\mathrm{a}}$ \\
\hline & Density $\left(\mathrm{kg} \cdot \mathrm{m}^{-3}\right)$ & $7,300-8,600^{a}$ \\
\hline & Enthalpy (kJ/kg) & $100-800^{a}$ \\
\hline & Viscosity $\left(\mathrm{kg} \cdot \mathrm{m}^{-1} \cdot \mathrm{s}^{-1}\right)$ & $2-3.25 \cdot 10^{-3 a}$ \\
\hline & Liquidus temperature $\left({ }^{\circ} \mathrm{C}\right)$ & 1,366 \\
\hline & Solidus temperature $\left({ }^{\circ} \mathrm{C}\right)$ & 1,266 \\
\hline \multirow[t]{4}{*}{ Mold } & Thermal conductivity $\left(\mathrm{W} \cdot \mathrm{m}^{-1} \cdot \mathrm{K}^{-1}\right)$ & $0.4-1.7^{\mathrm{a}}$ \\
\hline & Density $\left(\mathrm{kg} \cdot \mathrm{m}^{-3}\right)$ & $1,860-1,915^{\mathrm{a}}$ \\
\hline & Specific heat $\left(\mathrm{kJ} \cdot \mathrm{kg}^{-1} \cdot \mathrm{K}^{-1}\right)$ & $0.7-1.3^{\mathrm{a}}$ \\
\hline & Emissivity & 0.7 \\
\hline \multirow[t]{3}{*}{ Insulation wrap } & Thermal conductivity $\left(\mathrm{W} \cdot \mathrm{m}^{-1} \cdot \mathrm{K}^{-1}\right)$ & $0.1-0.5^{\mathrm{a}}$ \\
\hline & Specific heat $\left(\mathrm{kJ} \cdot \mathrm{kg}^{-1} \cdot \mathrm{K}^{-1}\right)$ & $0.9-1.3^{\mathrm{a}}$ \\
\hline & Emissivity & 0.7 \\
\hline Metal mold & $\mathrm{HTC}\left(\mathrm{W} \cdot \mathrm{m}^{-2} \cdot \mathrm{K}^{-1}\right)$ & $200-2,500^{a}$ \\
\hline Mold wrap & HTC $\left(W \cdot m^{-2} \cdot K^{-1}\right)$ & 100 \\
\hline Mold enclosure & $\operatorname{HTC}\left(\mathrm{W} \cdot \mathrm{m}^{-2} \cdot \mathrm{K}^{-1}\right)$ & 3 \\
\hline Wrap enclosure & $\mathrm{HTC}\left(\mathrm{W} \cdot \mathrm{m}^{-2} \cdot \mathrm{K}^{-1}\right)$ & 10.6 \\
\hline Enclosure & Emissivity & 0.9 \\
\hline Others & Units & Value \\
\hline Melt pouring velocity & $(\mathrm{mm} / \mathrm{s})$ & 1,700 \\
\hline Melt temperature & $\left({ }^{\circ} \mathrm{C}\right)$ & 1,549 \\
\hline Preheating temperature & $\left({ }^{\circ} \mathrm{C}\right)$ & 1,200 \\
\hline
\end{tabular}

The value depends on the temperature. 


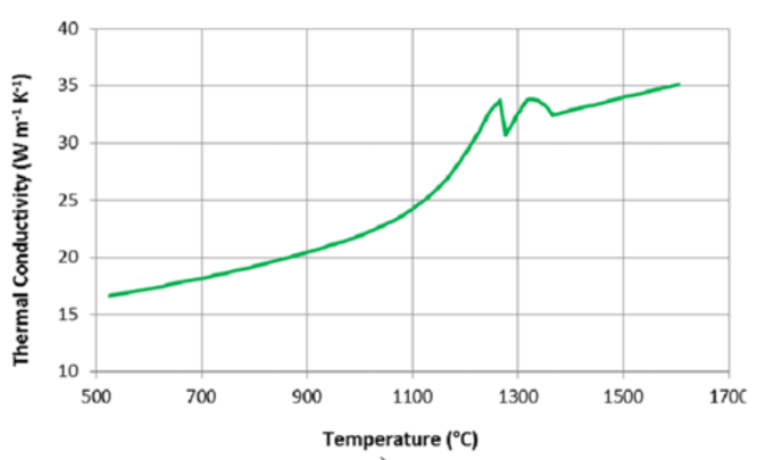

a)

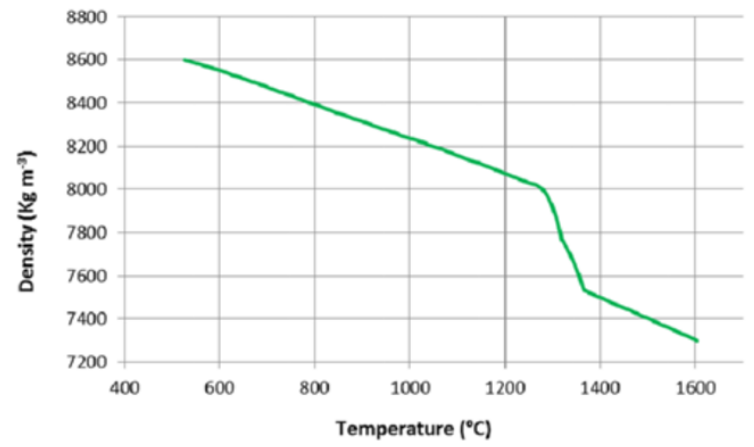

b)

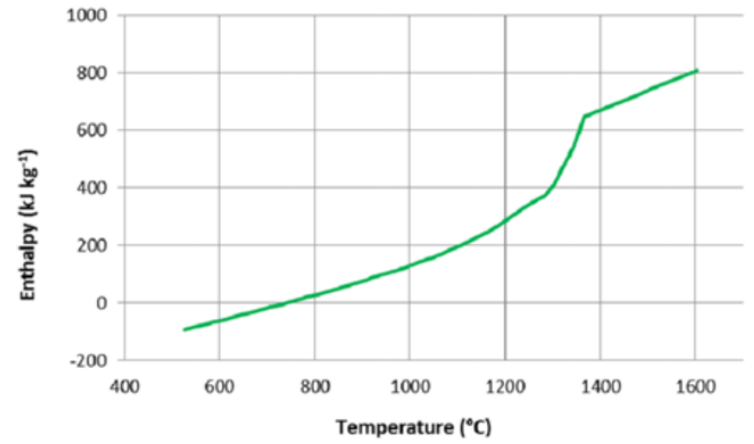

c)

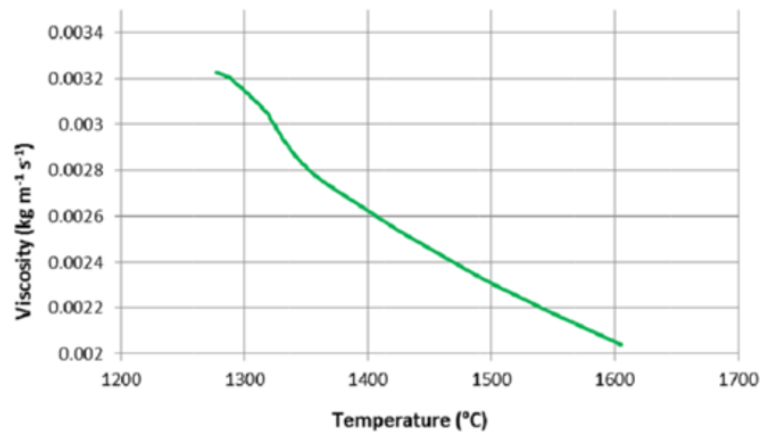

d)

Figure 2 Properties of MAR-M247 Ni-based superalloy vs. temperature. a) Thermal conductivity, b) density, c) enthalpy, and d) viscosity. 
Browne [30]. Figures 3 and 4 illustrate the variation of these properties with temperature for the ceramic mold and wrap, respectively.

It is known that pouring of the melt at high temperature leads to radiation heat loss. As this heat loss is not always correctly taken into account during the modeling process, the value of mold conductivity at high temperatures should be increased to account for this phenomenon. Experimental studies on this topic were earlier carried out by Precicast Bilbao and the experimental data from earlier measurements using the laser flash method (according to the ASTM E1461-07 standard) were considered. Analysis of all available data led to a final interval of mold conductivity in the range from 0.4 to $1.75 \mathrm{~W} \cdot \mathrm{m}^{-1} \cdot \mathrm{K}^{-1}$ (Table 2), which is in a very good accordance with the data provided by Konrad et al. [31] for low temperatures, and coincide with the experimental data measured by the laser flash method at high temperature (Figure 3a). The ProCAST database, data from the manufacturer of the kaolin wool, and Precicast Bilbao were considered to define the thermal conductivity of the insulation wrap. The final values of the thermal conductivity in the insulation wrap were in the range of 0.1 to $0.5 \mathrm{~W} \cdot \mathrm{m}^{-1} \cdot \mathrm{K}^{-1}$ (Figure $4 \mathrm{a}$ and Table 2).

A suitable temperature-dependent functional form (shown in Figure $3 \mathrm{~d}$ ) was used to determine the values of heat transfer coefficient (HTC) at the metal-mold interface. It is known that the HTC at the metal-mold interface is influenced by many factors such as casting geometry, pouring and preheating temperature, mold thickness, etc. Inverse and direct simulations were carried to obtain the final form of this function, which is plotted in Figure $3 \mathrm{~d}$ as a function of temperature. This function is slightly different from the one proposed by the ProCAST database as was demonstrated by Santos et al. [32] and Dong et al. [33]. Nevertheless, the final HTC at the metal-mold interface was in a very good agreement with the data reported in the literature for molten Ni-based superalloys in contact with ceramic molds. For example, Sahai and Overfelt [34] reported a HTC in the range $50-5,000 \mathrm{~W} \mathrm{~m}^{-2} \mathrm{~K}^{-1}$ for IN-718 Ni-based superalloy. The HTC at the mold-wrap, moldenclosure, and wrap-enclosure interfaces have less influence on the final result of the thermal model as shown by Yuang et al. [35]. Thus, it was assumed that they were constant with temperature and time, and the data from the ProCAST database were used (Table 2). Values of emissivity for mold, wrap, and enclosure were also taken from the ProCAST database, and the environmental conditions were fitted with those registered during experimental casting trials (Table 2). The pouring of the melt into the mold was introduced in the model by the definition of a planar surface on the top of the pouring cap, where a velocity to the liquid was applied to simulate the pouring process. The preheating temperature of the mold and temperature of melt poured into the mold were also specified (Table 2). The same filling steps performed during the experimental procedure were simulated by the software, using $2 \mathrm{~s}$ of filling time to introduce the molten alloy into the mold. Thus, the full solidification process was completed $830 \mathrm{~s}$ after the pouring. All the experimental data were taken into account during the simulations to synchronize the experimental data with the simulation results. The simulation process was operated by the ProCAST Parallel Solver with four processors $(2.40 \mathrm{GHz})$ and took nearly $11 \mathrm{~h}$ to simulate the whole thermal history of the NGV investment casting process.

\section{Experimental validation of the thermal model}

Experimental casting trials were carried out for validation of the thermal model as described above. Figure 5 illustrates the experimental temperature-time plots for metal, 


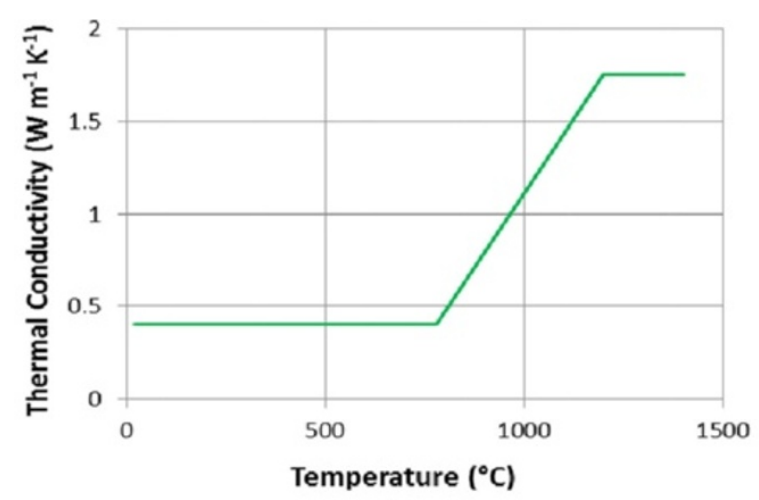

a)

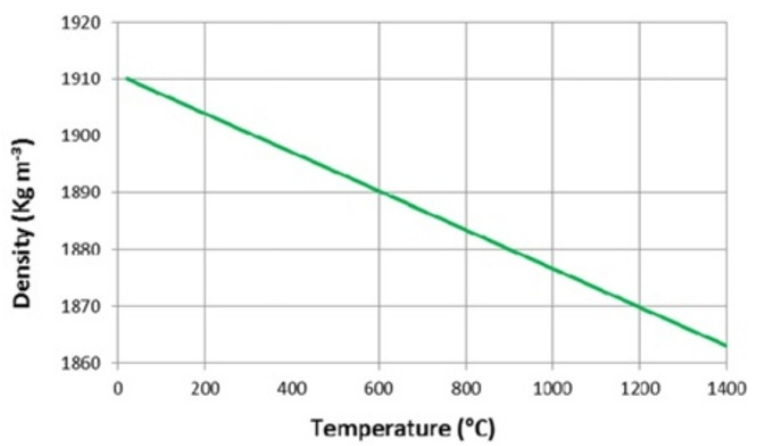

b)

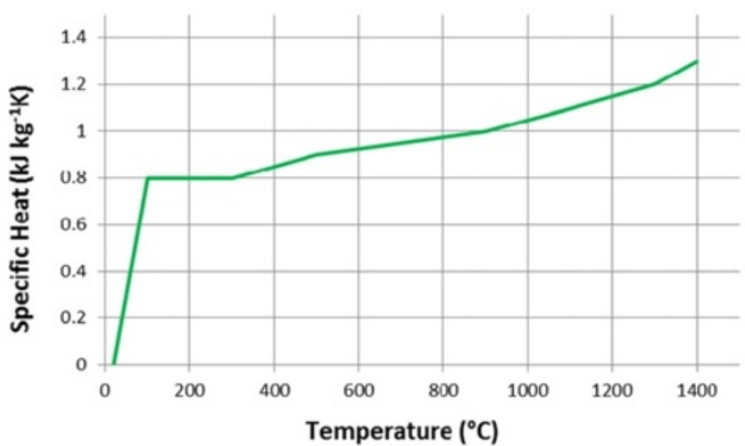

c)

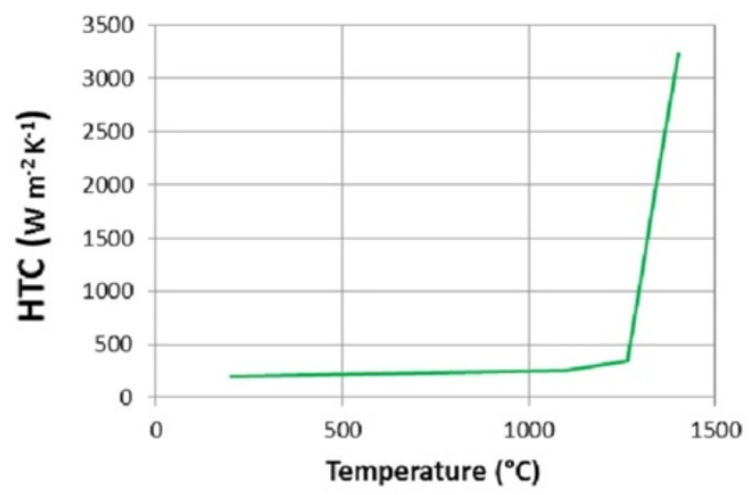

d)

Figure 3 Properties of ceramic mold vs. temperature. a) Thermal conductivity, b) density, c) specific heat, and $\mathbf{d}$ ) heat transfer coefficient (HTC) at the metal-mold interface. 


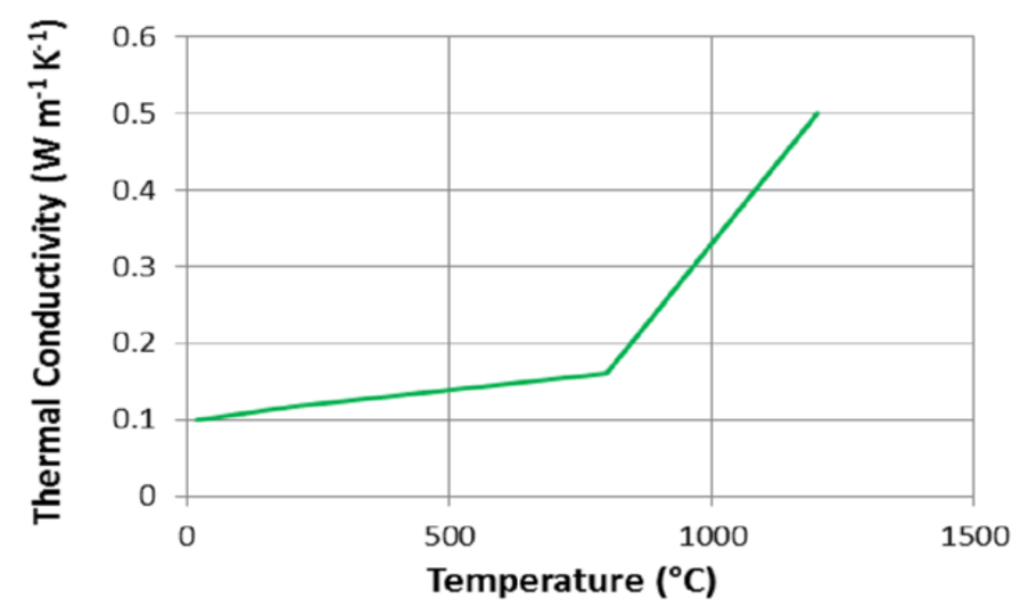

a)

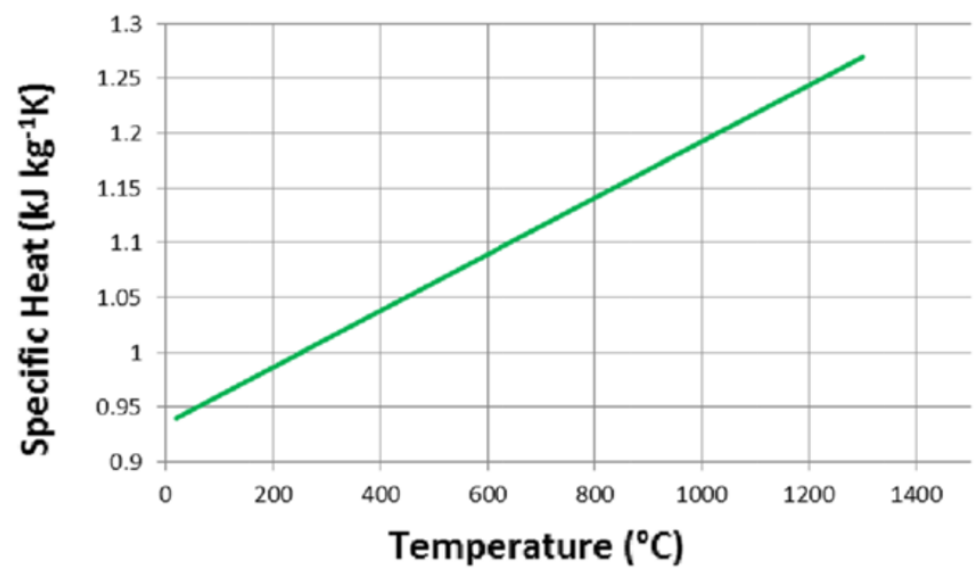

b)

Figure 4 Properties of wrap vs. temperature. a) Thermal conductivity and b) specific heat.

ceramic mold, and insulation wrap during investment casting. Temperature recording was started once the thermocouples were located in the defined spots. The thermocouple placed in the metal is close to reach the preheating temperature $1,200^{\circ} \mathrm{C}$, while the thermocouple placed in the mold records a temperature slightly over $1,100^{\circ} \mathrm{C}$. In the readings from the thermocouple fixed to the insulation wrap, temperature rises up to $900^{\circ} \mathrm{C}$. Significant difference of temperatures between metal and wrap was registered at the beginning since it took time to place correctly each thermocouple into its location. This loss of time leads to partial cooling of the mold that, in turn, increases the temperature gradient between metal and mold.

After the mold entered the vacuum casting furnace, vacuum was pumped and melt was poured into the ceramic mold. The thermocouples placed in the metal and wrap clearly registered this event by showing a rapid temperature rise, whereas the thermocouple located in the ceramic mold showed a temperature decrease (Figure 5). The liquidus-solidus transition in the metal can be easily identified in the experimental temperature-time plot because of the reduced slope. The cooling rate increases once the melt is solidified. 


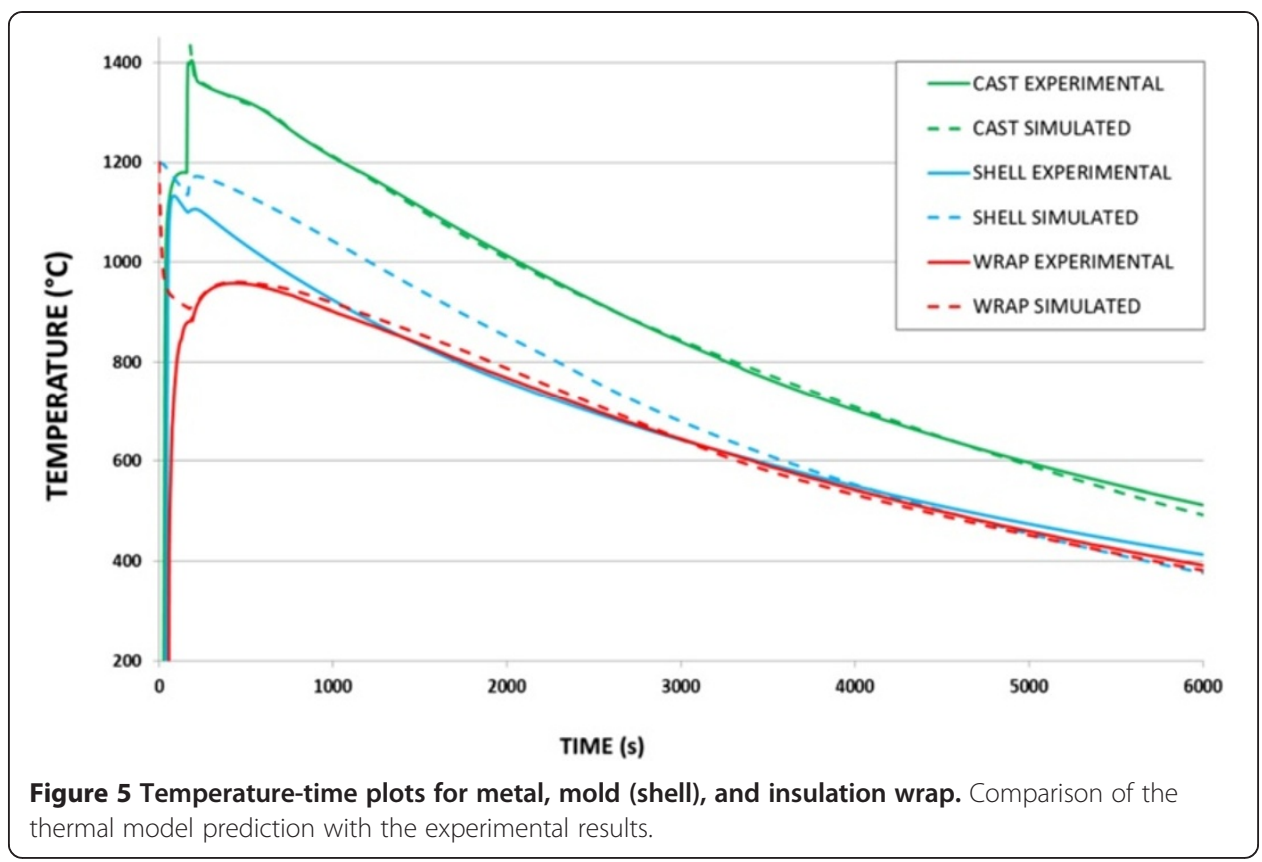

The temperature-time plots generated by the thermal model are compared with the experimental results in Figure 5. A very good agreement is observed for the thermal history in the metal and in the wrap, where the simulation results match very well the experimental results during first $6,000 \mathrm{~s}$ of the solidification/cooling process. However, a difference of nearly $100^{\circ} \mathrm{C}$ is found between the predicted temperature and the experimental data in the ceramic mold. Despite the close location of the thermocouple to the inner surface of the ceramic mold, the temperature registered by this thermocouple hardly achieves $1,100^{\circ} \mathrm{C}$, though the melt was poured into the ceramic mold at $1,459^{\circ} \mathrm{C}$. The reasons for such discrepancy are discussed in the 'Accuracy of the thermal model' section.

A proper prediction of the liquidus-solidus transition has to be achieved in a reliable thermal model. A deeper analysis of the liquidus-solidus transition is found in Figure 6, which shows a perfect match between simulation and experimental results. The most significant deviation between numerical predictions and experimental results occurs at $300 \mathrm{~s}$ after pouring, and the difference is just $4^{\circ} \mathrm{C}$.

Since the solidification process of the metal and its thermal history are correctly described, the thermal model can be further utilized to predict the microstructure and defects of the as-cast parts. The next section of this manuscript focuses on the ProCAST model for porosity prediction, which is developed on the basis of the thermal model.

\section{Model for porosity prediction}

\section{Description of the model}

The ProCAST tool was employed in this work to simulate the development of porosity during investment casting. The physical basis of the model is following. The key variable is the fraction of solid (FS) which extends from FS $=0$ for liquid to FS $=1$ for solid, as shown schematically in Figure 7. When the melt solidifies, pockets of liquid are created, surrounded by a mushy zone and then a solid shell. Automatically, the casting is divided into 'regions' having the FS $<1$. These 'regions' are bounded by isosurfaces. As 


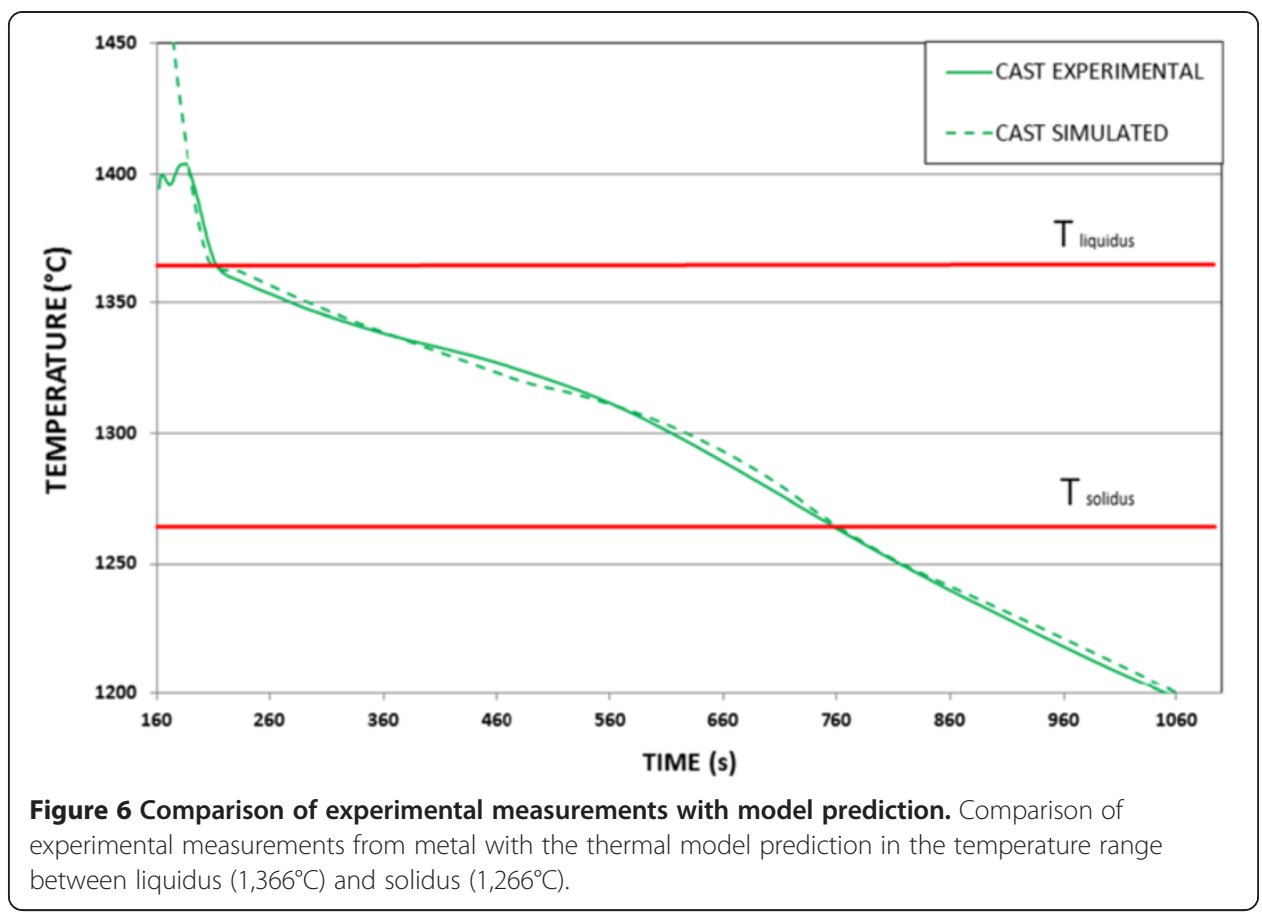

solidification proceeds and depending upon the complexity of the geometry, the number of 'regions' may increase with time, i.e. one 'region' can be split in more 'regions'. The 'region' disappears once all nodes are completely solidified.

The model is based on comparison of the local FS with a few parameters describing 'key stages' of solidification which determine the porosity in the cast. The first parameter, PI, is a measure of limit of local solid fraction under the surface until piping ${ }^{\mathrm{a}}$ on the surface can occur. In other words, the model predicts formation of pipe (empty nodes) while FS $<$ PI (Figure 7). In the present calculations, the default value recommended in the ProCAST database PI $=0.3$ was used, i.e. piping occurs until the solid fraction reaches $30 \%$. No porosity formation takes place in the bulk of the casting while local FS $<$ PI. The second important parameter, PF, is a limit of solid fraction until the liquid can still feed a hot area. PF $=0.7$ (the default value recommended in the ProCAST database) was used in the present simulations. The model predicts the formation of pipe in the form of a shrinkage pore on the surface while $\mathrm{PI}<\mathrm{FS}<\mathrm{PF}$ (Figure 7). If there are no nodes of the 'region' on the free surface having $\mathrm{PI}<\mathrm{FS}<\mathrm{PF}$, no pipe can be formed and the model predicts macroshrinkage in the bulk of casting (Figure 7). In this case, the macropore nucleates and grows at the highest point of the liquid pocket.

According to the model, microporosity can appear only in the zone having $\mathrm{PF}<\mathrm{FS}<1$. The third parameter FL, critical feeding length, is introduced into the model to predict microporosity. The FL value depends upon the size of the mushy zone and thus, the size of the casting. In the present calculations, $\mathrm{FL}=0.005$, following the value recommended in the ProCAST database. Two scenarios are possible in the bulk of casting:

1) There is still some mushy zone (liquid) below PF. Microporosity forms only at the distance higher than FL from the PF isosurface (see zone A for the corresponding situation in Figure 7). The amount of microporosity is equal to the density change 


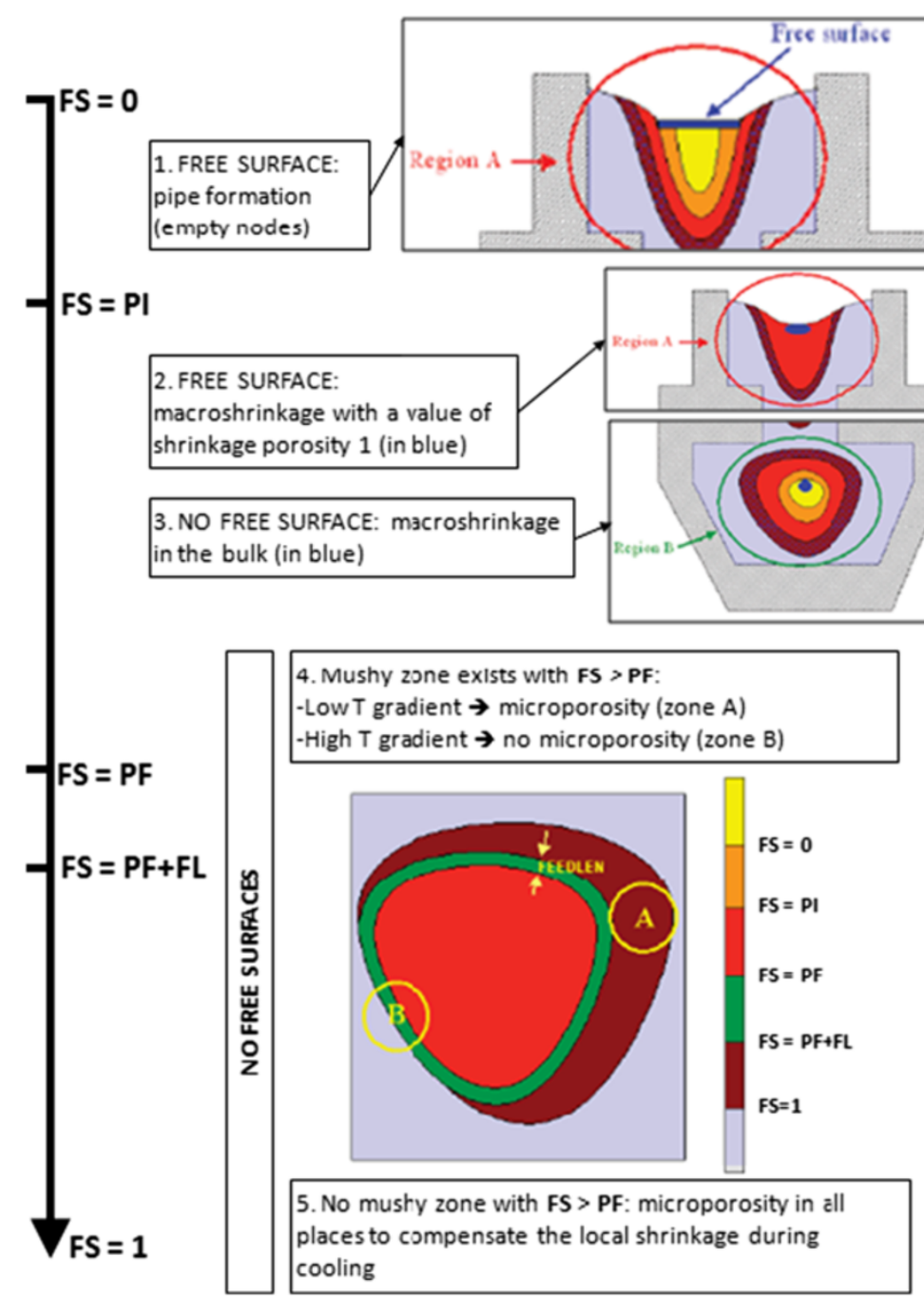

Figure 7 Schematic presentation of the porosity prediction model.

between the local solid fraction and 1. No micropores can form in the case of high-temperature gradients, since the distance between PF and solidus isosurface is smaller than FL (see zone B for the corresponding situation in Figure 7). On the contrary, low-temperature gradient promotes formation of microporosity (see zone A for the corresponding situation in Figure 7).

2) There is no more mushy zone in zones with $\mathrm{PF}<\mathrm{FS}<1$. In this case, the parameter FL is not active. In this case, there can be microporosity in the whole region with $\mathrm{PF}<\mathrm{FS}<1$ to compensate the shrinkage during cooling. The level of porosity is calculated based on the change of the density for each node as solidification takes place. This variation in the density of the material allows the software to compute the volume corresponding to shrinkage porosity as the limit value of PF is achieved in the nodes.

The modeling results are displayed in ViewCast software. The unit is volume fraction [\%]. The results are classified as follows: 
- the porosity values below $1 \%$ correspond to microporosity;

- the porosity values in the range between $1 \%$ and $2.3 \%$ correspond to shrinkage porosity;

- the porosity values above $2.3 \%$ correspond to the macroporosity.

The present tool was applied for porosity prediction in the as-cast NGVs, and the simulation outcomes are presented in the next section.

\section{Results and discussion}

Porosity characterization in the as-cast new generation NGV and experimental validation of the model

Figure 8 shows the porosity predictions (left) and the experimental data (right) of transversal section of a solid vane in the as-cast NGV. The optical micrographs corresponding to the trailing edge (zone a), middle part (zone b) and leading edge (zone c) are also plotted in Figure 8. The analysis of these results shows a good agreement between simulation predictions and experimental results in all zones. The highest level of porosity $(\leq 2.91 \%)$ is predicted for the middle part of the solid vane and it is in quantitative agreement with the experimental shrinkage porosity of $3.07 \%$ in this area (Figure $8 \mathrm{~b}$ and Table 3). The average pore size is $22 \mu \mathrm{m}$. Analysis of the histogram of pore size distribution shows that the frequency of pores decreases with increasing size and a few macropores with a size up to $196 \mu \mathrm{m}$ are present in the middle part (Figure $9 \mathrm{a})$. For the leading edge, lower levels of shrinkage porosity $(\leq 2.17 \%)$ are predicted by the model, but this prediction overestimates the experimental result, $0.63 \%$ (Figure 8a and Table 3). The average pore size slightly decreases to $20.4 \mu \mathrm{m}$ and the maximum pore size does not exceed $79 \mu \mathrm{m}$ (Figure 9b). Finally, shrinkage porosity was not predicted in the trailing edge and this is confirmed by experimental study (Figure 8a and Table 3).

Figure 10 illustrates the outcomes of porosity modeling for the longitudinal section of the solid vane along with the optical microscopy images for selected areas. A good correlation between simulation and experimental results is observed. The simulation results show the highest level of macroporosity $(\leq 2.90 \%)$ in the red zone (b). The experimental evaluation of porosity in the red zone (b) yields porosity of $4.87 \%$ with the average pore size of $113 \mu \mathrm{m}$ (Table 4). The frequency of pores decreases with increasing size and a few macropores with a size up to $280 \mu \mathrm{m}$ are present in the hot spot (Figure 11b). Macroporosity of $\leq 2.83 \%$ is expected in the zone (c) according to the model, whereas the experimental results show macroporosity of $4.82 \%$ (Table 4 ). The amount of the large pores decreases in this area (Figure 11c) and the average pore size is reduced to $27 \mu \mathrm{m}$, correspondingly (Table 4). A decrease of porosity should take place in zones a and $\mathrm{d}$ and shrinkage porosity of $\leq 2.43 \%$ is predicted, though the experimental characterization of these areas shows much lower values of porosity (Table 4).

The simulation results were also validated for the hollow vane of the new generation NGV (Figure 12). Generally lower porosity is predicted at the top $(\leq 2.17 \%)$ and bottom $(\leq 2.47 \%)$ sections of the hollow vane since the small thickness of the walls hastens the solidification process, thus reducing porosity. The highest porosity $(\leq 2.73 \%)$ is expected in the midsection of the hollow vane as it solidifies last. The experimental 

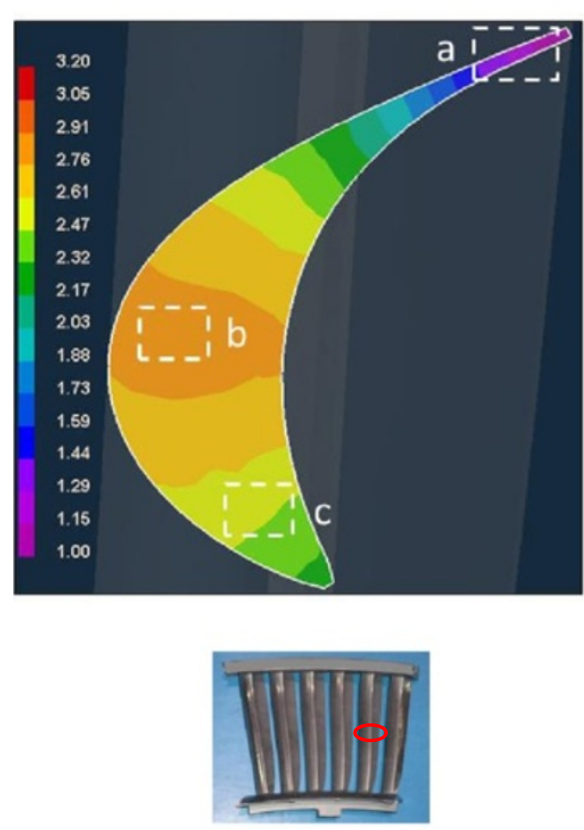

Figure 8 Porosity prediction by the ProCAST model and optical microscopy images of porosity. Porosity prediction by the ProCAST model (left) and optical microscopy images of porosity for the defined areas (right). The location of the analyzed section in the NGV is marked by red circle.

data of porosity in all these areas follow the trends predicted by the simulation (Figure 12), although the modeling results tend to overestimate the porosity in the hollow vane (Table 5).

\section{Accuracy of the thermal model}

The analysis of the simulation results and their comparison with the experimental data clearly show that the thermal history of the metal and wrap is very well described by the thermal model during the solidification and cooling processes (Figure 5). The differences between predictions and experimental measurements in the mold do not seem to be due to the model. The thermal plot measured from the ceramic mold seems to underestimate its real thermal history since the thermocouples record slightly higher temperatures for the insulation wrap compared to the ceramic mold in the time range of 1,300-3,000 s (Figure 5), which cannot be true. This discrepancy can be rationalized on the basis of the shortcomings of the experimental procedure utilized to measure the temperature in the ceramic mold. In particular,

1) Cement was used to fix the thermocouple to the ceramic mold;

2) Some 'air gaps' can appear between the thermocouple and cement due to significant thermal expansion/contraction; 
Table 3 The porosity characteristics of the transversal section of the solid vane on Figure 8

\begin{tabular}{llll}
\hline & Leading edge & Middle part & Trailing edge \\
\hline Local porosity fraction $[\%]$ & 0.63 & 3.07 & No porosity \\
Average pore size $[\mu \mathrm{m}]$ & 20.4 & 22.0 & - \\
\hline
\end{tabular}

3) There could also be some deviations from the correct positioning of the thermocouple in the ceramic mold during its fixing to the ceramic mold, since this operation has to be performed manually at extreme conditions in limited time.

The 'air gaps' and cement can significantly reduce the heat transfer from the mold to the thermocouple since they have lower thermal conductivity compared to the ceramic

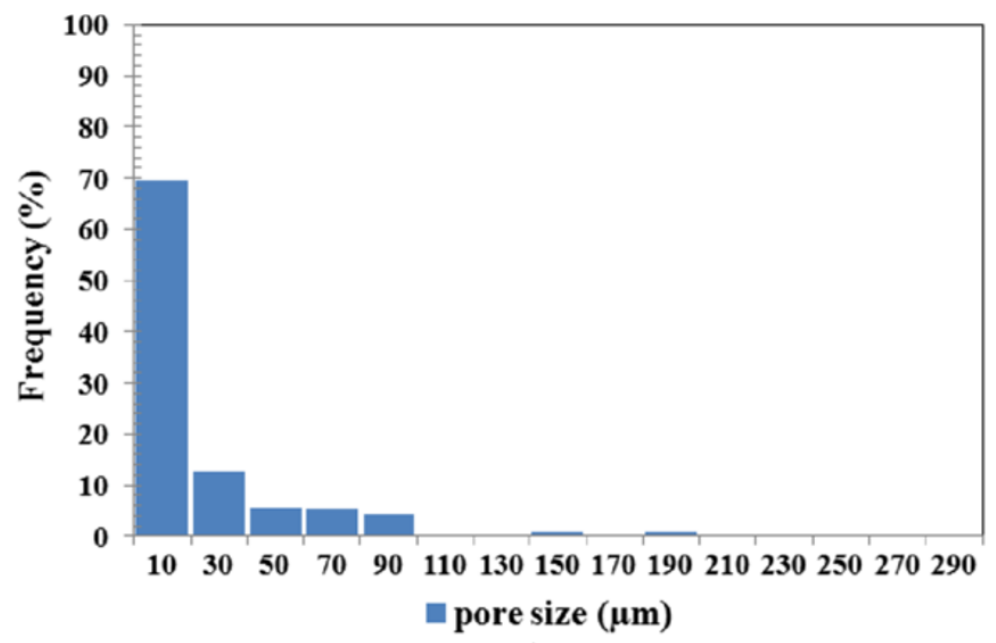

a)

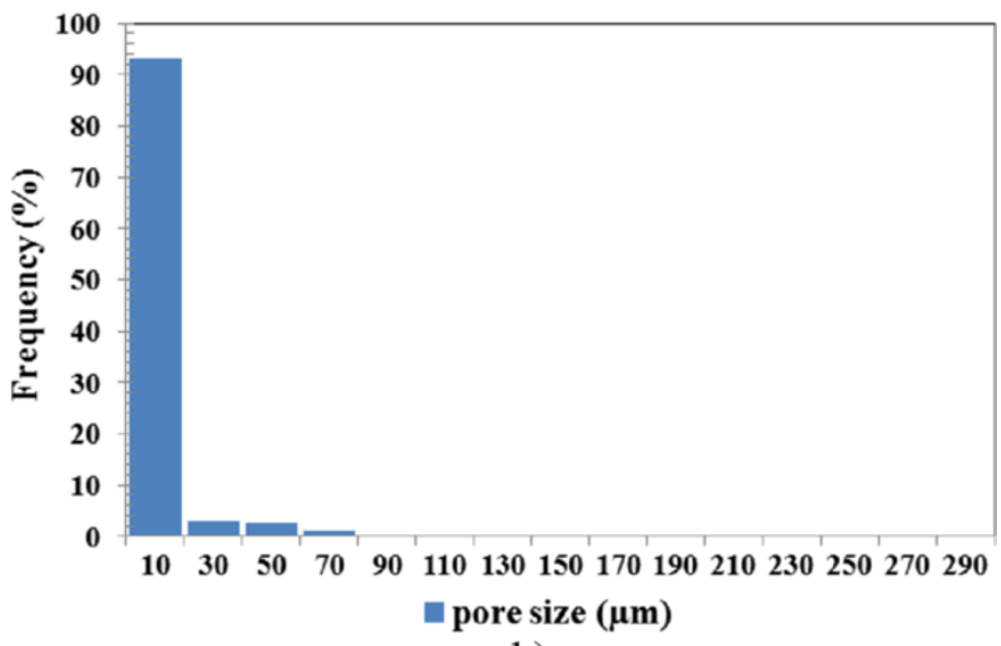

b)

Figure 9 Histograms of pore size distribution on transversal section of the solid vane. a) The middle part (Figure 8b) and b) the leading edge (Figure 8c). 


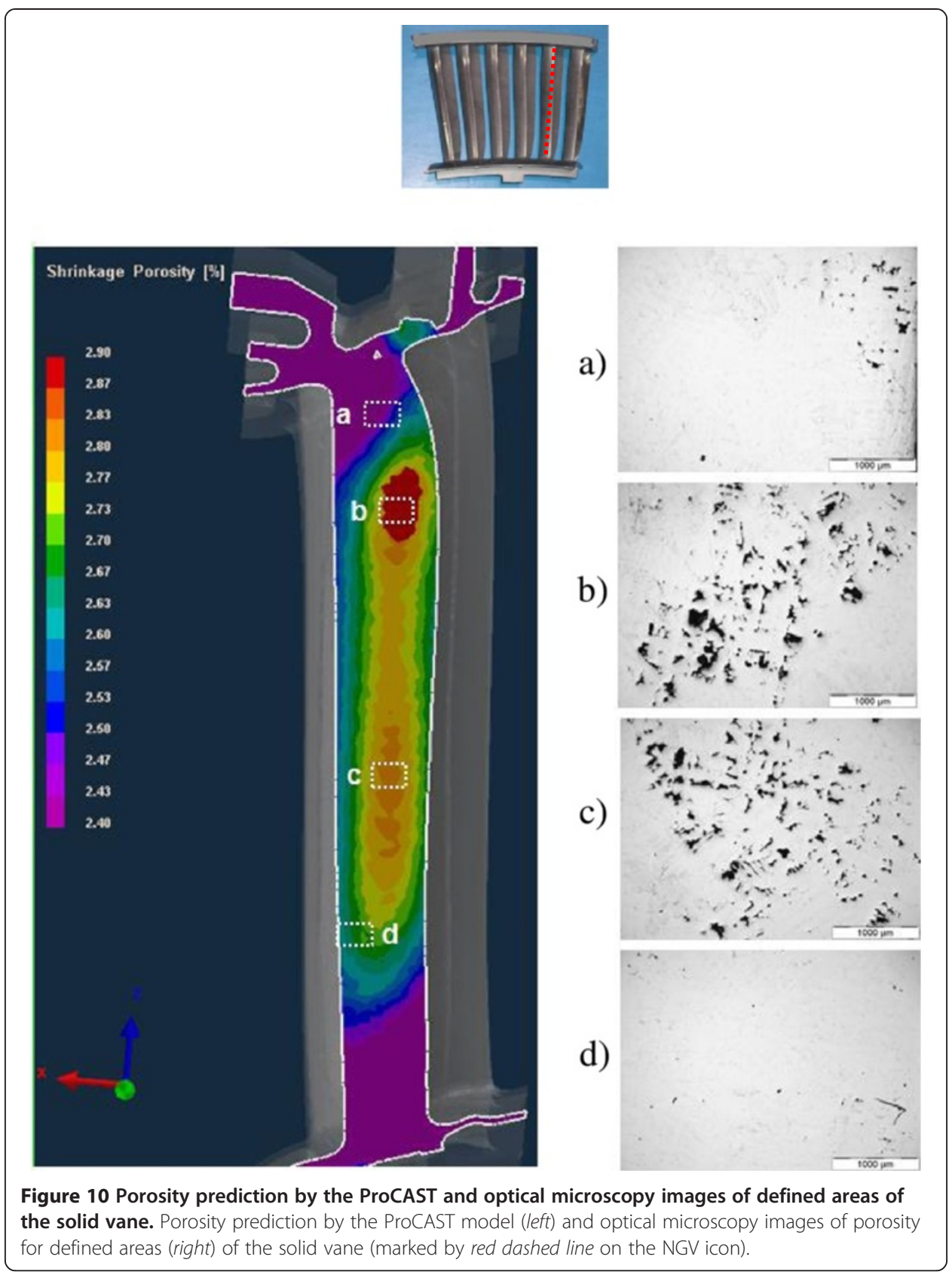

mold. Therefore, the experimental measurements on the mold can yield lower temperatures than the real temperatures, as seen from Figure 5. These shortcomings could also lead to the drop of temperature readings from the thermocouple placed in the ceramic mold at the moment of melt pouring which could result in thermocouple shifting due to thermal expansion of ceramic mold (Figure 5).

Table 4 The porosity characteristics of the longitudinal section of the solid vane on Figure 10

\begin{tabular}{lllll}
\hline Area & $\mathbf{a}$ & $\mathbf{b}$ & $\mathbf{c}$ & $\mathbf{d}$ \\
\hline Local porosity fraction $[\%]$ & 0.19 & 4.87 & 4.82 & 0.14 \\
Average pore size $[\mu \mathrm{m}]$ & 32 & 113 & 27 & 29 \\
\hline
\end{tabular}




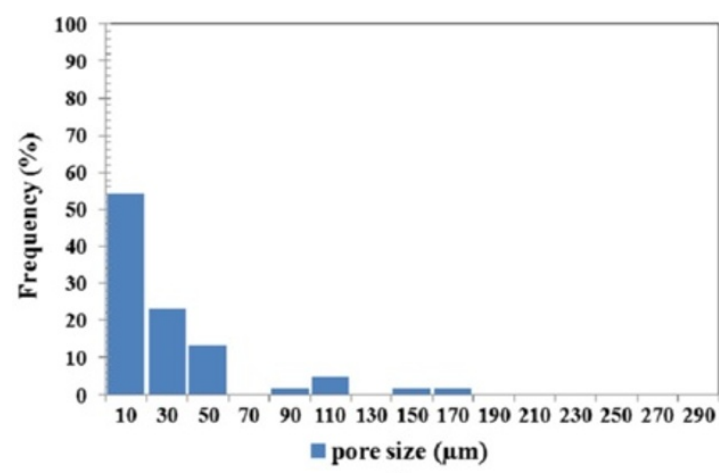

a)

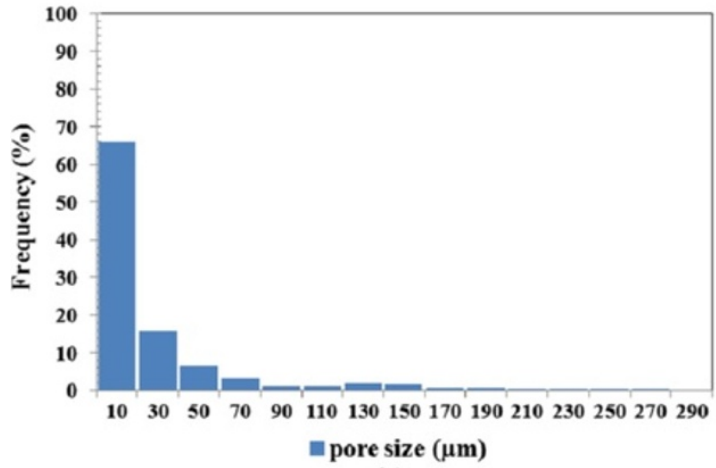

b)

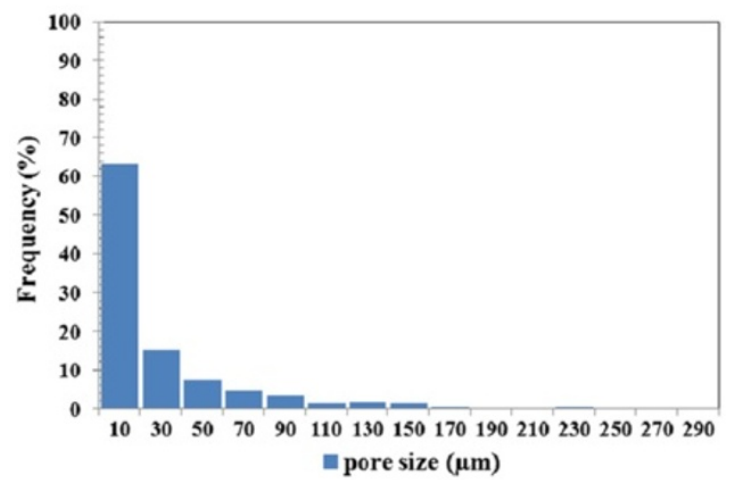

c)

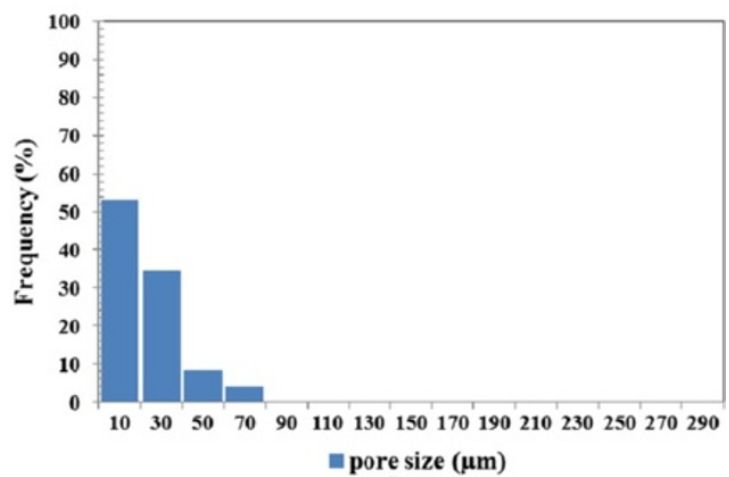

d)

Figure 11 Histograms of pore size distribution on the longitudinal section of the solid vane. a) Area on Figure 10a, b) area on Figure 10b, c) area on Figure 10c, and d) area on Figure 10d. 


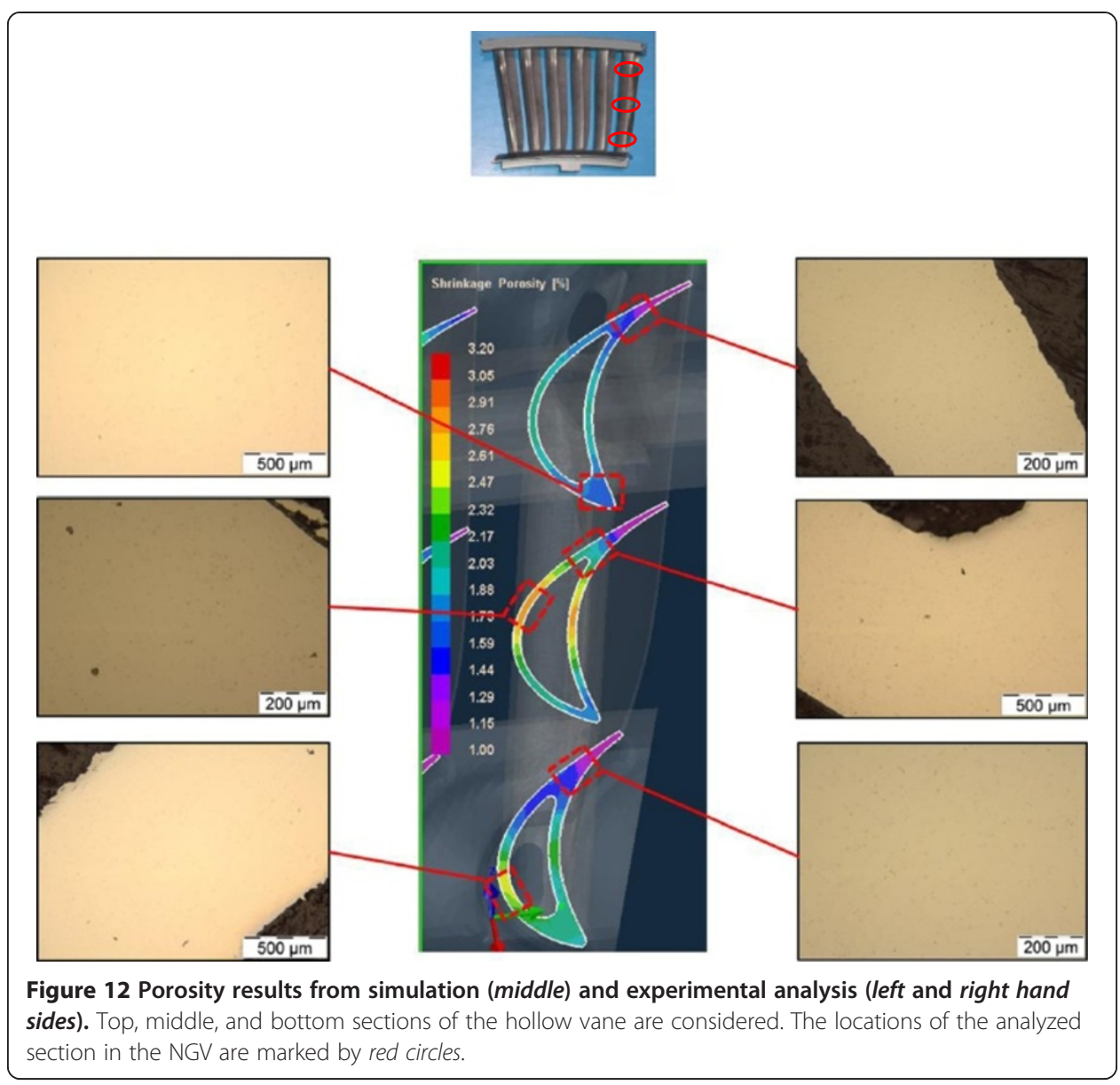

It should be noted that the possible 'air gaps' and the cement were not considered in the thermal model, since it would increase enormously the time required for calculations. Another experimental procedure should be developed for more accurate recording of thermal history in the ceramic mold. Nevertheless, the thermal histories of metal and wrap were accurately predicted as a result of the right selection of thermophysical parameters of the ceramic mold in the thermal model.

\section{Accuracy of the model for porosity prediction}

Analysis of the overall porosity prediction shows that the model predicts well the location of hot spots and areas prone to porosity formation throughout the NGV. These areas are located mainly in the solid vanes and this was confirmed by the experimental characterization of the as-cast NGV. A very good match between the simulation predictions and the experimental results was found in many NGV areas. However, the model tends to slightly underestimate porosity in the areas located in the thickest parts of the

Table $\mathbf{5}$ The porosity characteristics of the transversal section of the hollow vane on Figure 12

\begin{tabular}{llll}
\hline Area & Top & Middle & Bottom \\
\hline Average porosity fraction [\%] & 0.06 & 0.08 & 0.08 \\
Average pore size $[\mu \mathrm{m}]$ & 19 & 17 & 15 \\
\hline
\end{tabular}


NGV (Figure 10b). This discrepancy could be related to liquid pools which can be formed in those areas during solidification, as reported recently by Kang et al. [22]. Another shortcoming of the model is the overestimation of shrinkage porosity in the thinnest parts of the NGV, which are the hollow vanes with a wall thickness nearly $1 \mathrm{~mm}$. This effect could be explained by formation of skin which can significantly affect the local thermal history of the metal in the thin parts. It should be noted that the rapid skin formation due to freezing of melt with a colder ceramic mold is not taken into account by the model.

All in all, it can be outlined that the simulation tool for porosity prediction can be successfully utilized for further improvement of NGV design. Its application can significantly reduce the number of expensive experimental casting trials which are typically required to find the suitable casting parameters and to develop a manufacturing route for investment casting of complex shape parts at industrial scale.

\section{Conclusions}

Investment casting of NGV from Ni-based superalloys was simulated by means of a finite element model. The simulation strategy is targeted to predict the heat exchange during solidification and cooling and the porosity. The casting assembly, consisting of the hollow ceramic mold with NGV-shape interior and insulation wrap, is created and meshed. The thermophysical parameters and boundary conditions are defined for all the parts of the casting assembly, and simulation is carried out using ProCAST. Experimental casting trials are performed for validation of the developed models.

The thermal history of the metal and the insulation wrap during investment casting was accurately predicted. The critical thermal-physical parameters of the casting system were obtained either from the literature or by an inverse simulation procedure by comparing the simulation results for simple casting geometries with experimental data. The hot spots and areas with enhanced porosity which are located in the thickest parts of the NGV were accurately predicted. In addition, the porosity predictions were in good agreement with the experimental results in many NGV areas. The shortcomings of the porosity predictions include a slight underestimation of porosity in some very thick areas and an overestimation of shrinkage porosity in the thinnest parts of the NGV. It is concluded that the developed modeling tool can be successfully utilized for further improvement of NGV design, allowing to minimize the number of casting trials.

\section{Endnote}

${ }^{a}$ Piping is the formation of pipes during solidification. Pipes are open-air shrinkage defects which form at the surface of the casting and burrow into the casting. 
guidance. All authors contributed to the manuscript. The final version was prepared by IS and $\mathrm{J}$ and approved by all authors. All authors read and approved the final manuscript.

\section{Acknowledgements}

This investigation was carried out in frame of the VANCAST project (EU, FP7, ERA-NET MATERA+). SM and IS acknowledge gratefully the Spanish Ministry of Economy and Competitiveness for financial support through the Ramon y Cajal fellowships. Prof. A. Zryd (Maxwell Technologies SA) and Dr. A. Faes (CSEM SA) are greatly acknowledged for the inverse simulations of experimental casting trials of easy geometry parts as those results constituted the seed for experimental work which had led to this manuscript.

\section{Author details}

${ }^{1}$ University of Applied Sciences and Arts Western Switzerland, Sion, Switzerland. ${ }^{2}$ CALCOM-ESI, Lausanne, Switzerland. ${ }^{3}$ Precicast Bilbao, Bilbao, Spain. ${ }^{4}$ IMDEA Materials Institute, C/Eric Kandel 2, Getafe 28906, Madrid, Spain. ${ }^{5}$ Department of Materials Science, Polytechnic University of Madrid, Madrid, Spain.

Received: 24 July 2014 Accepted: 3 October 2014

Published online: 20 November 2014

\section{References}

1. Razak AMY (2007) Industrial gas turbines: performance and operability. Woodhead Publishing Limited, Cambridge, UK

2. Reed RC (2006) The Superalloys: Fundamentals and Applications. Cambridge University Press, Cambridge, UK

3. Pattnaik S, Karunakar DB, Jha PK (2012) Developments in investment casting process - a review. J Mater Proc Tech 212:2332-2348, doi:10.1016/j.jmatprotec.2012.06.003

4. Anglada E, Meléndez A, Maestro L, Domiguez I (2013) Adjustment of numerical simulation model to the investment casting process. Proc Eng 63:75-83, doi:10.1016/j.proeng.2013.08.272

5. Rafique MMA, Iqbal J (2009) Modeling and simulation of heat transfer phenomena during investment casting. Int J Heat Mass Transf 52:2132-2139, doi:10.1016/j.jiheatmasstransfer.2008.11.007

6. Stefanescu DM (2009) Science and Engineering of Casting Solidification, 2nd edn. Springer Science + Business Media, New York, NY, USA

7. Piwonka TS, Flemings MC (1966) Pore formation in solidification. Trans AIME 236(8):1157-1165

8. Pellini WS (1953) Factors which determine riser adequacy and feeding range. AFS Transactions 61:61-80

9. Niyama E, Uchida T, Morikawa M, Saito S (1981) Predicting shrinkage in large steel castings from temperature gradient calculations. AFS Int Cast Met J 6(2):16-22

10. Carlson KD, Beckermann C (2009) Prediction of shrinkage pore volume fraction using a dimensionless Niyama criterion. Metall Mater Trans A 40:163-175, doi:10.1007/s11661-008-9715-y

11. Kubo K, Pehlke RD (1985) Mathematical modeling of porosity formation in solidification. Metall Mater Trans B 16:359-366, doi: 10.1007/BF02679728

12. Lee PD, Hunt JD (2001) Hydrogen porosity in directionally solidified aluminium copper alloys: a mathematical model. Acta Mater 49:1383-1398, doi:10.1016/S1359-6454(01)00043-X

13. Lee PD, Chirazi A, Atwood RC, Wang W (2004) Multiscale modeling of solidification microstructures, including microsegregation and microporosity, in an Al-Si-Cu alloy. Mater Sci Eng A 365:57-65, do:10.1016/j.msea.2003.09.007

14. Carlson KD, Lin Z, Beckermann C (2007) Modeling the effect of finite-rate hydrogen diffusion on porosity formation in aluminum alloys. Metall Mater Trans B 38:541-555, doi:10.1007/s1 1663-006-9013-2

15. Pequet C, Rappaz M, Gremaud M (2002) Modeling of microporosity, macroporosity, and pipe-shrinkage formation during the solidification of alloys using a mushy-zone refinement method: applications to aluminum alloys. Metall Mater Trans A 33:2095-2106, doi:10.1007/s11661-002-0041-5

16. Couturier G, Rappaz M (2006) Effect of volatile elements on porosity formation in solidifying alloys. Model Simul Mater Sci Eng 14(2):253-271, doi:10.1088/0965-0393/14/2/009

17. Couturier G, Rappaz M (2006) Modeling of porosity formation in multicomponent alloys in the presence of several dissolved gases and volatile solute elements. TMS Annual Meeting, San Antonio, TX, USA, pp 143-152

18. Stefanescu DM (2005) Computer simulation of shrinkage related defects in metal castings - a review. Inter J Cast Metal Res 18(3):129-143

19. Lee PD, Chirazi A, See D (2001) Modeling microporosity in aluminum-silicon alloys: a review. J Light Metals 1:15-30, doi:10.1016/S1471-5317(00)00003-1

20. Overfelt RA, Sahai V, Ko YK, Berry JT (1994) Porosity in cast equiaxed alloy 718. In: Loria EA (ed) Proceedings of the TMS Meeting., p 189

21. Monastyrskiy VP (2010) Modeling of porosity formation in Ni-based superalloys. In: Choi JK (ed) Proceedings of the 8th Pacific Rim International Conference on Modeling of Casting and Solidification Process., p 89

22. Kang M, Gao H, Wang J, Ling L, Sun B (2013) Prediction of microporosity in complex thin-wall castings with the dimensionless Niyama criterion. Materials 6:1789-1802

23. Calba L, Lefebvre D (2008) Modeling the investment casting process. ESI-GROUP Resource Center, Paris

24. Harris K, Erickson GL, Schwer RE (1984) MAR-M247 derivations-CM247 LC DS alloy, CMSX single crystal alloys, properties and performance. In: Gell M, Kortovich CS, Bricknell RH, Kent WB, Radvich JF (eds) Proceedings of the 5th International Symposium on Superalloys, TMS., p 221

25. Handbook ASM (2010) Metals Process Simulation, vol 22B. ASM International, Ohio, USA

26. ProCast user Manual \& Technical Reference (2007) Version 6.1. ESI software, France

27. Rappaz M, Bellet M, Deville M, Snyder R (2002) Numerical modeling in materials science and engineering. Springer-Verlag, Berlin, Germany

28. Dantzig JA, Rappaz M (2009) Solidification. EPFL-Press, Lausanne, Switzerland

29. Handbook ASM (2008) Casting, vol 15. ASM International, Ohio, USA 
30. O'Mahoney D, Browne DJ (2000) Use of experiment and an inverse method to study interface heat transfer during solidification in the investment casting process. Exper Thermal Fluid Sci 22:111-122, doi:10.1016/S0894$1777(00) 00014-5$

31. Konrad CH, Brunner M, Kyrgyzbaev K, Völkl R, Glatzel U (2011) Determination of heat transfer coefficient and ceramic mold material parameters for alloy IN738LC investment castings. J Mater Proc Tech 211:181-186, doi:10.1016/j.jmatprotec.2010.08.031

32. Santos CA, Quaresma JMV, Garcia A (2001) Determination of transient interfacial heat transfer coefficients in chill mold castings. J Alloys Compd 319:174-186, doi: 10.1016/S0925-8388(01)00904-5

33. Dong Y, Bu K, Dou Y, Zhang D (2011) Determination of interfacial heat-transfer coefficient during investmentcasting process of single-crystal blades. J Mater Proc Tech 211:2123-2131, doi:10.1016/j.jmatprotec.2011.07.012

34. Sahai V, Overfelt RA (1995) Contact conductance simulation for alloy 718 investment casting of various geometries. Tran Amer F 103:627-632

35. Yuang XL, Lee PD, Brooks RF, Wunderlich R (2004) The sensitivity of investment casting simulations to the accuracy of thermophysical properties values. In: Proceedings of the International Symposium on Superalloys, TMS., p 951

doi:10.1186/s40192-014-0025-5

Cite this article as: Torroba et al:: Investment casting of nozzle guide vanes from nickel-based superalloys: part I - thermal calibration and porosity prediction. Integrating Materials and Manufacturing Innovation 2014 3:25.

Submit your manuscript to a SpringerOpen ${ }^{\circ}$ journal and benefit from:

- Convenient online submission

- Rigorous peer review

- Immediate publication on acceptance

- Open access: articles freely available online

- High visibility within the field

- Retaining the copyright to your article

Submit your next manuscript at $\gg$ springeropen.com 